\title{
Depression, Folk Psychiatry and the Task for 4E Philosophy of Psychiatry
}

\author{
Maja Bialek \\ University of Białystok, Poland \\ m.bialek@uwb.edu.pl
}

Received 3 December 2018; accepted 9 January 2019; published 9 December 2019

\begin{abstract}
The aim of my paper is to define three key problems concerning depression and to show how phenomenological and 4E theories of depression can be used to help us with them. I employ the Sellarsian concept of a synoptic view - a good synoptic view of depression should bring together the manifest image ("folk psychiatry") and the scientific image. The first problem is that currently there exist serious gaps in both images-our mainstream conceptions of depression are lacking and their reception by the general public is oversimplified and overoptimistic. The second problem is that the explanatory needs of the general public regarding depression could not ever be satisfied by the current scientific imageas I show using the case-study of the enthusiastic reception of Mira Marcinów's 2017 book presenting the often outlandish $19^{\text {th }}$ century Polish theories of depression. It turns out that certain outdated but vivid terms and ideas concerning melancholy actually may be more helpful in many ways than what current biomedical psychiatry has to offer. The third problem is how to rectify the first problem given the existence of the second problem - that is, how to make space for a less biomedical and reductionist approach to depression without risking an overly skeptical, anti-scientific turn within folk-psychiatry. I conclude that although phenomenological and embodied theories could not ever directly influence the manifest image of depression, they need to be included within the scientific image - and then they could become the perfect basis for a truly synoptic view.
\end{abstract}

Keywords: depression; folk psychiatry; 4E psychiatry; history of psychiatry; reductionism in psychiatry. 


\section{The Search for a Synoptic View of Depression}

It is a Sellarsian idea that philosophy should offer a synoptic view in which scientific and manifest images of things are combined. ${ }^{1} \mathrm{I}$ believe that psychiatry is right now very much in need of such view, for three interconnected reasons. Firstly, I will claim that the manifest image of psychiatric illnesses does not really offer what the general public needs of it and may indeed be harmful. Secondly, this is partly so because of how it is influenced by the scientific image and what specific elements have been adapted as its core features. Thirdly, the scientific image of mental illnesses, offered by mainstream, reductionist neurobiological psychiatry, has now found itself in a precarious position and heavy attacks have been launched against it. Given that there is a strong relation between manifest and scientific images, the rising scepticism about the latter could wreak havoc on the former.

In this essay I wish to concentrate on depression because of its special importance as the most prevalent, most widely recognised and perhaps also the most studied mental illness of the $21^{\text {st }}$ century. I will begin by examining our current manifest image of depression and draw out a concept of "folk psychiatry" which will be analogous to "folk psychology" as it was understood by Lewis or Fodor. I also wish to examine in detail the case study of Polish $19^{\text {th }}$ century psychiatry and the fascinating insights into the possible gaps in our manifest image of depression offered by M. Marcinów’s 2017 analysis of those theories. I will then elaborate on the reasons for those gaps and, in particular, on the deficiencies of the current scientific image which may eventually turn out to be dangerous also on the manifest level, especially given the rise of antipsychiatry. It is relatively uncontroversial that it is the now well-established 4E paradigm of psychiatry that seeks to modify, correct and supplement the scientific image of depression in a nonreductionist way. I would, however, like to show that $4 \mathrm{E}$ approaches have something more to offer. They are ideal candidates for a truly synoptic view, because they take into account the relevant explanatory needs that lay behind both the manifest and the scientific image of depression. Thus, they may not only help with providing explanations but also in reshaping how the public thinks.

\subsection{The Manifest Image of Depression and Folk Psychiatry}

The term „folk psychiatry” has been already employed by Haslam, Ban, and Kaufmann (2007) in order to describe their proposed model of how the general public approaches mental disorders. My use of the term will be slightly different-more akin to Lewis's (1972) and Fodor's (1985) idea of a folk-theory. Folk psychiatry is the way we explain the beliefs, experiences and behaviours of people suffering from depression outside strictly scientific and medical contexts. It is neither as old, as general nor as deeply rooted in our thoughts and language as folk psychology has been claimed to be, but it has made its way into everyday explanations and influences our understanding of ourselves and our fellow travellers. Folk psychiatry is obviously reflective of the scientific theories of our times

${ }^{1}$ I am referring here, of course, to Sellars, 1962. 
(which I shall discuss in much detail) and it is also absolutely crucial in the communication between the rapidly increasing number of patients and their doctors. Its importance-and the reason I focus on it in this paper-is not purely sociological, although it is naturally of tremendous importance with respect to the way people suffering from depression are treated. More than anything, a study of folk psychiatry reveals many cracks in the mainstream psychiatry itself and the potential dangers it may run into. In fact, we may think of folk psychiatry as a variation on the Sellarsian idea of a "manifest image" as opposed to (but not in conflict with) the "scientific image" of mental disorders.

However, using the notion of "folk psychiatry," instead of focusing simply on the "manifest image of depression" will help me specify the deficiencies of the latter. A folk-theory is not just a view on something, it has a particular job to do-it is employed in order to explain certain phenomena (in our case: the behaviours and experiences of people suffering from some kind of mental disturbances). It needs to have explanatory virtues. Scientific insights are gradually changing folk theories partly because they really help achieve coherence, fill in explanatory gaps and offer practical advantages in everyday life. In this light it is understandable, that folk psychiatry may be influenced more strongly by the scientific image provided by psychiatry than folk psychology is by scientific psychology. Psychiatric illnesses are especially difficult to grasp and to deal with in everyday life - and have always posed a serious challenge for folk theoreticians. Therefore, folk psychiatry is strongly dependent on some understanding of the scientific image and reception thereof.

\section{Folk Psychiatrists and the Explanatory Gap in the Manifest Image of Depression}

If we asked the man on the Clapham omnibus today what depression was, he would most probably adopt one of two stances. On the one hand, he might prove to be one of the "folksceptics" who believe that ,depression" is just a weakness that might be overcome if one's will is strong enough or some such thing - let me call them, for the sake of this paper, "depression denialists." However, if he had been educated in any way, for example if he had read some kind of an informational brochure akin to the one issued by $\mathrm{NIMH}^{2}$ (Buck, 2008), he would probably explain that depression is a real illness involving the occurrence of certain symptoms and caused by some kind of defect in the brain - a disease that may be cured or managed with the help of antidepressants. Perhaps he would even go so far as to explain that it has something to do with an imbalance of neurotransmitters and/or specifically the lack of serotonin. A US survey conducted in 2009 showed that only $22 \%$ out of 1015 respondents agreed that "People diagnosed with depression would recover if they could just 'snap out of it" "whilst as many as $82 \%$ agreed (or strongly agreed) that "Depression is a serious medical condition that requires treatment" (Harris Interactive, 2009). This medicalised approach to depression is also prominent in the aforementioned model reconstrued by Haslam (Haslam, Ban, \& Kaufmann, 2007) — and the author proposes the

\footnotetext{
${ }^{2}$ The National Institute of Mental Health is a U.S. federal agency for research on mental disorders.
} 
obvious explanation that this is simply a consequence of the way the public absorbs the most common views on depression expressed by the scientific community. An interesting meta-analysis performed by Schomerus et al. also shows that the public understanding of mental illness has evolved noticeably towards a biological model (an overwhelming majority of respondents - especially in the United States - agrees that depression is a disease of the brain), which in turn has improved the public awareness of the fact that in case of psychological distress one should seek professional, medical help (Schomerus et al., 2012). However, another, more disturbing conclusion of the analysis was drawn: despite greater knowledge of the biomedical conception of psychiatric disorders, attitudes towards people diagnosed with mental illness are not improving - in fact, it might even be suggested that they are gradually growing worse (it is definitely so in case of schizophrenia). It is even suggested that promoting a much less reductionist and medicalized, psychosocial view of depression would be more helpful in fighting the stigma (Longdon \& Read, 2017). It may be concluded, therefore, that the biomedical model features prominently in the manifest image of mental illness in general-and of depression in particular, although much remains to be examined in more detail.

Firstly, it must be made clear that - as is always the case with folk theories and manifest images - the concept of depression as it functions in folk psychiatry can only be a simplified version of what is actually claimed by biomedically oriented psychiatrists. It is natural to assume that the folk understanding of the mainstream biological and reductionist psychiatric conception of depression is probably a little crude and vague - but I would also risk the thesis, that the overall idea of how well depression is explained in the scientific image might be overly optimistic. Furthermore, I put forth that it is overly optimistic not because of some kind of "folk wishful thinking" but because the way the biomedical model is presented and described in educational materials, in mass-media and also by practicing psychiatrists to their patients, seems to often be overconfident.

The whole reductionist project of biological psychiatry was built on a promise that psychological pathologies might be treated in an analogous fashion to physiological diseases - since the advent of pharmacological methods of treating psychopathologies it has been considered a matter of time when a complete neurobiological explanation of particular symptoms and syndromes is found. However, as of today these goals have not been achieved and the debate about the way depression should be understood, diagnosed and treated seems to be more lively than ever, with a new wave of antipsychiatry creeping up among the psychiatric community itself (this issue will be discussed further in the following sections of this paper). Despite this, the layperson's view, as I have pointed out above, is simpler than ever, "if you are depressed, it means your brain is sick; go see a doctor, she will give you pills which fix the chemistry of your brain." This optimism is strongly influenced by the decisive tones of informational brochures and the fact that biologically oriented psychiatry seems to have finally succeeded in being accepted as a branch of medical science. Obviously, it is also reinforced by the PR efforts of pharmaceutical companies - it has been observed (cf. Greenberg, 2011) that highly disputable claims about the 
neurobiological mechanisms of both depression and the effects of antidepressants are being presented as robust facts. Although officially the etiology of affective disorders has not been established yet, it is not uncommon that the hypothesis that depression is caused by specific kind of neurotransmitter imbalance is being presented as a hard, scientifically proven truth. Therefore, such claims are not, strictly speaking, parts of the real scientific image of depression - they are however often accepted by folk-psychiatrists as scientific.

We also have to keep in mind that the general public's attitude towards science in general has become strongly polarised (Rutjens, Heine, Sutton, \& van Harreveld, 2018), partly due to the instigating influence of social media (see, for example, Brossard \& Scheufele, 2013). More and more issues are being presented as black or white choices, all-or-nothing questions; people are eager to differentiate "scientific views" which must be accepted without any further doubt from hypotheses they consider to be dangerous superstitions, although they are rarely capable of performing such assessments without bias or oversimplification. It is because of all these factors combined that the "scientifically-oriented" folk-psychiatric view of depression is becoming non-negotiable and therefore straightforward to the point of being naïve. The only alternative is some version of "depression denialism," or at least this is the immediate accusation.

Secondly, and even more importantly, it must be observed that an oversimplified neurobiological view of depression present in folk psychiatry is insufficient on various levels. It is lacking not only from the point of view of practicing psychiatrists (for example, because it might lead to unrealistic expectations on the part of their patients), but it also cannot serve the purposes that folk theories normally serve. Folk psychology-according to the classical arguments for it-is a theory whose task is to explain our actions and behaviour (Fodor, 1985; Jackson \& Pettit, 1990). Concepts such as "belief" or "desire" are employed because they help to do so, they tell us something about the workings of our minds. However, "beliefs" and "desires" are concepts we understand intuitively (according to the Davidsonian tradition "belief" is actually one of our most basic concepts, one whose possession constitutes the basis of our cognitive abilities). The same could not be said of "neurotransmitters" or "neurobiological mechanisms" that are making their way into folk psychiatry. The theory of neurotransmitters is very far from anything we might reasonably call a "manifest" image of anything. There also exist concepts that are often used to explain the actions of a depressed person and that at the same time belong in the same level of intuitive explanation as the folk-psychological "beliefs" and "desires"-I am referring here to terms describing emotional states and attitudes such as "sadness" or "despair." However, there is an important difference I need to note here.

In the case of psychological concepts, the efforts of reductionists are usually aimed at seeking out the neurobiological correlates of "beliefs" and "desires." Therefore, when the scientific image is slowly incorporated into the manifest image in psychology, folk-psychological "beliefs" are gradually being replaced by "activities of the brain." The situation is much more complex when pathological states are concerned. It is the very essence of 
diagnostic criteria for depression included in the fifth edition of the Diagnostic and Statistical Manual of Mental Disorders (DSM V) and the tenth edition of the International Statistical Classification of Diseases and Related Health Problems (ICD 10) that the behaviour of the sick person cannot be explained by sadness or grief alone. In many cases grasping the difference between what constitutes a normal emotional reaction and one that requires medical intervention is a contentious issue even among specialists (and it is known to be the subject of a heated debate ${ }^{3}$ ). Moreover, the assumption that such differences exist constitutes the core difference between the group I have nicknamed "depression denialists" and the "folk psychiatrists." The experience and the beliefs ${ }^{4}$ of a depressed person are conceived of as transcending regular experience and beliefs. This is how the layperson is able to recognise that someone needs medical assistance. Therefore, the terms that the manifest image of depression borrows of the simplified scientific image are actually crucial; without them folk psychiatry could not really serve its explanatory purposes at all. However, as I have suggested, the manifest image, thus supplemented, ceases to be a manifest image at all. "An imbalance of neurotransmitters" cannot be treated as a valid folk-explanation of depression; it is rather an ignotum per ignotum.

It's time to formulate my three conclusions of this section. Firstly, the folk-psychiatric understanding of depression is an oversimplified and overly optimistic version of what mainstream psychiatry actually has to offer. Secondly, neither regular folk-psychological language nor folk-psychiatric explanations actually serve the natural purpose of folk theories with respect to depression: they do not help us explain the beliefs and behaviours of a depressed person. I claim that this opens up a - potentially dangerous - explanatory gap and in the following sections I will proceed to elaborate on why this is so and what is needed to bridge it.

\section{The Manifest Image of Depression and the History of Polish Psychiatry}

The case study I wish to analyse in order to elaborate on my claim that an explanatory gap of sorts does exist in the context of understanding depression, and that it is actually felt by real people, is the way the Polish public greeted the publication of the first volume of Mira Marcinów's monumental history of Polish psychiatry in 2017. Although this huge volume is in fact a lengthy, meticulous study of forgotten Polish 19th century theories of melancholy, ${ }^{5}$ it attracted much attention not only from specialists in the field but also from regular

\footnotetext{
${ }^{3}$ I am referring here to the controversial decision to withdraw the so-called „bereavement exclusion” from the DSM V which means that from now on even if the patient's depressed state can be attributed to a traumatic event it still can be the ground of diagnosing Major Depressive Episode. However, it is not clear if the exclusion is decisive (Wakefield \& Frist, 2012) and to what extent it should be considered dangerous (as potentially leading to overdiagnosing depression; Uher, Payne, Pavlova, \& Perlis, 2014).

${ }^{4}$ Depression may lead not only to unrealistic appraisals of one's life and prospects but also to full-blown delusions such as Cotard's syndrome - that is, the conviction that one is dead or nonexistent.

${ }^{5}$ Because of the drastic changes in psychiatric terminology world-wide it is impossible to conclude with certainty
} 
readers and even from the mass media. It is extremely rare in Poland that an author of a scientific, historical volume is interviewed on breakfast TV and it needs to be regarded as very significant. ${ }^{6}$ What is most important in the context of my paper is that the findings that attracted the most interest were not so much the dated explanations of the nature of the illness or the description of (now somewhat outlandish) treatment methods - but the very concepts that were employed by the psychiatrists whose work Marcinów investigated. It is nearly impossible to translate the old Polish psychiatric terms rediscovered by Marcinów-such as "człowiek zadumowy," "smutnodur," "tczyca," "śledziennictwo"- they are striking, rich and thoroughly alien even to the modern Polish language. However, at the same time all the words ring familiar, because they are deeply rooted in concepts and meanings that do exist to this day, the notions of reverie, sadness and dolour, nostalgia, spleen and many others. Marcinów's readers seemed to greet all those new-old concepts not only with curiosity but also with gladness. Because of their meaningful roots - and of the multidimensional cultural and historical contexts they evoke - these new-old words have finally filled a certain void that had been there for a long time. The laden concept of "depression" evokes only the neurobiological notion belonging to the medicalized view of the human psyche. The old concepts, with their characteristic, slightly poetic air, are so welcome for at least three reasons.

Firstly, most of them somehow attempt to capture the actual experience of depression, they refer to particular feelings associated with melancholy and emphasise that in melancholy those feelings become somehow disproportionate. For example, "smutnodur" is a mix of "sadness" ("smutek") and "pain," but the part that signifies pain, "dur," is not the common Polish word for pain ("ból") but a much more specific one, still used in the Polish name for typhoid fever, "dur brzuszny" (whose main symptom is abdominal pain). Secondly-and this is a complex subject upon which Marcinów herself elaborates in her book-they provide a rich web of cultural associations, particularly those stemming from the era which tended to romanticize all psychiatric illnesses. What now is labelled with harsh, sterile concepts such as "an affective disorder" can be seen again in the context of the long forgotten ideals and myths of the suffering creative genius and the like. On the other hand, some of the theories are much closer to the harsh reality. Melancholy in people who did not happen to be poets (and particularly in women) is connected to their poor social circumstances, both as an effect and as a cause. It is mentioned that Dorota S. and Kunegunda J., both patients of doctor B. Frydrych, the author of the first Polish companion to psychiatry published in 1845, were lead to despair and suicide thoughts because of poverty and lack of support. Joanna O.

that all the disorders described and considered by the authors mentioned in Marcinów's book are somehow to be identified with the modern notion of depression. It is most emphatically not the author's idea to do so- quite the contrary, we are invited to reflect upon all the ways the categorisation of disorders is influenced by historical factors.

\footnotetext{
${ }^{6}$ Although I need to note that there may have also been other factors involved - after the author revealed herself as an expert on Polish psychiatry she has sometimes been pressured to diagnose prominent politicians. This, in turn, is actually an example of two tendencies in folk-psychiatry I mentioned in the previous section. Firstly, that there is now a strong tendency to treat any signs of mental troubles as analogous to symptoms of biological diseases and refer them to specialist assessment. Secondly, that this does not help to lift any of the stigma; on the contrary, a psychiatric diagnosis would be considered a blow to a politician's image.
} 
developed sadness and delusions after certain unspecified "domestic conflicts." Tomasz Ostafin's and Ignacy Mazurkiewicz's madness, on the other hand, were the causes of their crimes and, in consequence, imprisonment (Marcinów, pp. 91-92, 109-113).

Finally, it is refreshing on the meta-level to see how depression can be conceptualized, understood and treated in so many vastly different ways. In particular, we are reminded how deeply the conceptions of psychiatric illnesses are shaped by not only historical contexts, but also by particular interests that motivate their creation and the use that they are to be put to - in case of many $19^{\text {th }}$ century authors those interests and uses revolved around cognitive impairments on the one side and around moral and legal questions on the other.

This third reason deserves a more in-depth analysis. As Marcinów emphasises, Polish $19^{\text {th }}$ century psychiatry was developing locally, the authors did not, as a rule, collaborate or learn from one another, there also was no one foreign influence that would dominate the whole Polish field (which in itself was also naturally fragmented because of historical and political reasons). Therefore, the book offers a whole kaleidoscope of approaches, definitions and terms, and, most importantly, a variety of authentic stories describing the fates of patients. This is particularly striking for a layperson who is accustomed to the oversimplified neurobiological view, and even more so for a philosopher of psychiatry routinely employing clear cut DSM or ICD definitions in her everyday work. Marcinów's book allows us to focus on whole histories of individuals, written up and interpreted by their $19^{\text {th }}$ century doctors, to consider not only certain actions or states, but the patients' whole lives, their family circumstances and their moral standing (which was of special interest at the time). It also forces us to do so, to resist the temptation of quickly classifying people according to our modern rigid lists of symptoms and diagnoses.

In the "Introduction" Marcinów declares that her project is inspired by Arthur O. Lovejoy's concept of the history of ideas and Michel Foucault's "intellectual history." Therefore, her purpose is not simply to trace certain notions that we now find accurate in the writings of $19^{\text {th }}$ century authors, nor is it of course an invitation to reject modern psychiatry in favour of the "good old methods" involving, for example, the use of surprising amounts of opium. Marcinów brings forth the claim that the history of ideas is a history of theories that, in the long run, had lost - of rejected concepts, of wrong notions. It is most often the case that scientifically sound conceptions are not the ones that are actually prevalent with and accepted by the general public; the reception of scientific discoveries is even now a much slower process than the changes to the scientific canon. This is why it is the study of secondrate, abandoned theories that often offers us the window into the collective mind of a certain era. This is also why those theories may still be relevant at least in one way: they uncover what questions pertaining to psychiatric disorders were once perceived as crucial, what kind of language proved to be useful, which approaches were found fruitful. In short, the history of Polish $19^{\text {th }}$ century psychiatry as well as its reception both help us understand what people need and want to know about depression, what they want to describe - in other words, how they wish construct their actual manifest image of this disorder. Much of it is now forgotten, and much - justly so. However, the needs are still there. 
I would like to spell out at least three specific needs. Firstly, more focus on the first-person experience and a more meaningful language to explain the beliefs and actions of people suffering from depression. Secondly, theories that enable us to see depression in a wider, social and even cultural context - perhaps thus finally freeing it from the stigma that the current folk-psychiatric understanding is unable to free it of. Thirdly, a tactic for dealing with the fact that the way depression is conceptualised is highly dependent on various external factors and biases deeply grounded in our contemporary social reality.

In this light, Marcinów's book (and any good book on the history of psychiatry in general) might be considered a step towards understanding, changing and enriching the folk-psychiatric understanding of depression. It is surprising how quickly it actually seems to begin to do so-for example, Ł. Żurek's literary review of a 2018 novel by Olga Hund describing Hund's experience of a contemporary Polish mental institution already includes a reference to Marcinów's book. Even more surprisingly, Żurek also refers directly to one of the authors studied by Marcinów and already mentioned in this section, B. Frydrych. Frydrych's psychological analyses of the etiology of what he called "ponurowatość" or melancholy in women is, above all, deeply reflective of the typical preconceptions of his time concerning women's excessive emotionality and troubled sexuality, perhaps to the point where his views cease to be relevant at all. Still, at the same time, he is an author who devoted much attention to the circumstances of his patients. Frydrych's psycho-social account of the reasons why women end up in psychiatric wards, in which social station, violence, lack of support and poverty are mentioned, evidently proved to be more informative for Żurek than the DSMs (Żurek, 2018).

However, this is where we need to proceed with caution-for obvious reasons it simply would not do to allow the current manifest image of depression to be replaced or even supplemented at will by just any theory that employs aesthetically pleasing concepts or which romanticizes depression in an appealing fashion. The obvious worry would be, simply, that much of the contents of the historically disproved and outdated theories is now considered wrong or harmful, and with good reason. For example, various assumptions made by $19^{\text {th }}$ century authors about women's disturbed sexuality and emotional life as possible causes of melancholia might lead our folk-psychiatrist to adopt the "denialist" stance or even reinforce the sexist misconception that it's not "manly" to seek professional help. Also, despite many public campaigns, it is still often a challenge to encourage people suffering from depression to seek professional help. Therefore, any attempt at undermining the monopoly of mainstream neurobiologically oriented psychiatry might be considered a risky or irresponsible endeavour. Moreover, as I will explain in the following section, the main reason for special caution in promoting any nonstandard views on depression is the aforementioned precarious position of neurobiological psychiatry itself which in turn endangers the stability of the broadly speaking scientific content inherent in the current folk-psychiatric view.

The case-study of our forgotten manifest image of depression revealed more about the contemporary explanatory gap and the insufficiency of our current manifest image for the needs 
of folk-psychiatry. As I claim, there is a real need for a richer language, for more satisfying ways of explaining the behaviours and experiences of people suffering from depression. To put it simply, it seems that the manifest image shaped mainly by the mainstream simplified scientific image of the disorder cannot fulfil the role of a folk theory. At the same time, given that the prevalence of depression is constantly rising, the need for explaining the behaviours and experiences of depressed people will only become more and more poignant. It is, therefore, worrisome, what kind of stereotype-based speculation or other unsound, harmful ideas might be introduced in order to fill in the gaps in the manifest image.

However, my thesis is not limited to the issue of folk-psychiatry. In fact, it is in no small part because of the deficiencies of the scientific image that our manifest image is currently failing. And, as I will make clear in the next section of this paper, the scientific image that was supposed to be provided by the contemporary neurobiologically-oriented psychiatry is becoming increasingly vulnerable and frail on its own. The perspectives of ever achieving a synoptic view without introducing major changes to both images are now seeming as bleak as ever.

\section{The Danger: Antipsychiatry, the Rising Scepticism about the Scientific Image of Depression and Their Consequences for the Manifest Image}

The concept of "antipsychiatry" is associated mainly with Thomas Szasz and his book The Myth of Mental Illness (Szasz, 1961) although the author himself was not as radical in opposing mainstream reductionist psychiatry of his time as he is often perceived to be, especially by laypeople. Apart from questioning whether "mental illness" is indeed a valid concept or is it simply a dangerous tendency of medicalizing normal problems of living, the movement has been primarily directed against coercion in psychiatry. The contemporary wave of antipsychiatry is, however, less blunt and it also appears to be much more empirically-oriented. As I will point out, there remains a worry about the tendency in psychiatry to medicalize phenomena which are in fact typical human struggles. However, the most direct arguments against mainstream biomedical psychiatry concentrate around the very real weakness in what was supposed to be its core: its scientific soundness. In 2016 two papers have been published by the Lancet Psychiatry in which a large group of authors enumerated no less than 17 challenges for psychiatry involving fundamental problems in diagnosing, explaining and treating mental disorders (Stephan et al., 2016a; Stephan et al., 2016b). Particular attention was devoted to the fact that in many cases biological markers of particular illness have not been found. I have already mentioned that the investigations into the neurobiological etiology of depression have so far been unsatisfactory which in itself provokes many doctors to seek new avenues for developing psychiatry. Authors such as Bracken and Thomas (2001) even propose that in light of so many disappointments concerning the biomedical model, the era of reductionist psychiatry needs to be ended, and a new, postpsychiatric one is to begin - although they do distance themselves from radical antipsychiatric views. 
The issue that seems to raise particular scepticism is whether the treatments offered by mainstream neurobiological psychiatry are actually as effective as it is believed in folk psychiatry. This question has always attracted a lot of interest because of the long-lasting feud between the proponents of strictly pharmacological methods and psychotherapistsa conflict that now seems to have been resolved, the consensus being that in many cases pills and certain kinds of talk-therapies are actually equally effective and that the particular treatment method should be chosen on a case by case basis. Nevertheless, this very factthat what supposed to be targeting the only real, neural cause of the illness is only as efficient in treating it as psychotherapy-has been raising some doubts. Many papers and books have been published in order to expose how the current research on antidepressants is at best of questionable quality, that the popular-folk-psychiatric - understanding of their workings is actually reflective more of the effectiveness of advertising campaigns than of actual scientific facts and that the therapeutic benefits of those drugs are routinely overestimated while their side effects are being glossed over (cf. Moncrieff, 2013; Kirsch, 2009, 2014; Greenberg, 2011). In the spring of 2018 an impressive network meta-analysis was published by Cipriani et al., who compared the results of a large number of drug trials testing antidepressants against placebo, and its concluding, triumphant "they are effective!" was heralded with relief even by some of the mass media (thus again proving how strongly medicalized the folk-psychiatric conception of depression is). However, despite the resounding positive conclusion the results themselves are not as unequivocally encouraging - many of the drugs turned out to be only slightly better that placebo, many of the experiments raise doubts as to their methodological quality and, what is perhaps the most disturbing, there still is no real explanation of why particular drugs perform in a particular way. ${ }^{7}$ The large STAR ${ }^{*} \mathrm{D}$ study ${ }^{8}$ involving in its first stage over 3000 subjects suffering from depression revealed that although most of the patients ended up receiving effective treatment, it required much trial and error-different treatments were equally effective overall and there was no way to determinate which of them might be appropriate in the case of a specific person. On the one hand, it is only an often exaggerated and oversimplified report of the general optimistic conclusions of such studies that influence the folkpsychiatric understanding, not the much less unequivocal scientific proof behind them. On the other hand-any reasonable or even unreasonable doubts concerning the empirical bases of psychiatry may also be unnecessarily damaging to their popular reception, as is often the case with other branches of medical sciences.

Another weak point of the mainstream model is the unclear status of the DSM (especially since its third edition - cf. Shorter, 2005) and its approach to mental disorders. There is a disturbing discrepancy between the categorical way in which symptoms are grouped into

\footnotetext{
${ }^{7}$ The authors invite all interested parties to evaluate their data for themselves (they are freely accessible on the Mendeley Data platform). Many conclusions of immediate practical importance may be drawn by specialists from the countless comparisons available.

${ }^{8}$ For details about the study see the NIMH page https://www.nimh.nih.gov/funding/clinical-research/practi$\mathrm{cal} / \mathrm{stard} /$ allmedicationlevels.shtml
} 
syndromes and clear, quantitative diagnostic criteria are offered to doctors, and the actual justification for such classifications and guidelines. Even given the new dimensional approach, the diagnostic methods suggested by traditional neurobiologically oriented psychiatry lend themselves easily to criticism and, in particular, to the charge of arbitrariness. ${ }^{9}$ They were supposed to stem directly from neuroscience - but so far their hard empirical basis has been simply unconvincing. There are also reasons to believe that it might be harder than expected to provide such basis, because more and more research emphasises that depression is a multifaceted phenomenon and that the individual variability among people diagnosed according to the DSM criteria is so extreme that it is even slightly difficult to find similar cases (cf. Fried \& Nesse, 2015). This contrast between what has been promised and what is delivered compounds the disappointment, and the scepticism surrounding psychiatry at the scientific level. It may be noted that any kind of subtle debate about complex issues such as the possibly multifactor etiology of depression do not translate well into the manifest image. In folk theories there is simply no place for uncertainties and scientific hypotheses awaiting further research.

Naturally, many efforts are being made to remedy the situation - a notable example is the $\mathrm{RDoC}$ (Research Domain Criteria) project aimed at bringing together research on mental disorders conducted on various social, psychological and neurobiological levels of explanation (cf. Insel et al., 2010). The RDoC project is actually intended also as a way to revolutionise and reorganise the current categorisation of mental disorders. However, as for now, given the strength of the offensive launched by sceptics and the surge of antiscientific attitudes in general, the position of the scientific image offered by mainstream psychiatry is precarious indeed.

As I have already suggested in the conclusion of the previous section, because of the deficiencies of the scientific image, we are facing a risk that our manifest image of depression might be modified in unwanted ways. Given the above-mentioned doubts surrounding the very essence of the neurobiological approach, we may fear that the new folk psychiatry would turn against pharmacological treatment methods, adopt an oversimplified, overly optimistic or naïve view of the illness ${ }^{10}$ and cause much harm to many suffering people.

It is, therefore, high time to discuss what philosophers of psychiatry have to offer regarding a new synoptic view of the disease, in which both the manifest and the scientific images are much enriched.

\footnotetext{
${ }^{9}$ One of the most controversial issues was raised, for example, by Allen Frances who expressed concern whether the changes introduced gradually to subsequent editions of the DSM do not lead us to medicalizing more and more behaviours which should not really be considered pathological (Frances, 2013).

${ }^{10}$ Such disquieting views are already emerging in the popular culture, advertised by celebrities such as Beata Pawlikowska.
} 


\section{Phenomenological, Embodied and Enactive Approaches to Depression; a Synoptic View}

Although expressions such as "4E cognition" and "4E psychiatry" are relatively new, this trend in philosophical thinking about various psychopathologies has been on the rise since a long time now. The four "E's" stand for an "embodied," "embedded," "enacted" and "extended" approach - and, in order to better grasp the origins of this family of conceptions, a very important " $\mathrm{Ph}$ " should also be added, referring to "phenomenology," in at least two senses of the term. Firstly, most of the theories actually rely on Husserl's philosophy and concepts (often drawing also from Merleau-Ponty, Heidegger and Sartre). Secondly, all of them emphasise the crucial role of studying the subjective experience of mental disorders which is usually loosely identified with phenomenology in a more general, methodological sense. As I have established in previous sections, the lack of evocative, meaningful language and the tendency to disregard or even ignore the validity of the first-person experience of depression in favour of statistical diagnostic manuals were the crucial elements causing the emergence of the gap between what serves as folk psychiatry - and what is actually needed to form a useful manifest image, let alone a fully-fledged synoptic view. It might seem dubious at first. Are highly philosophical, abstract theories grounded in a particularly difficult school of thought able to actually enrich or supplement either the scientific ${ }^{11}$ or the manifest image of depression and therefore ever become a part of folk psychiatry? Indeed, in this section I will show that certain claims of 4E philosophers and psychiatrists could even be met by more than an incredulous stare from an ordinary naively over-reductionist folk-psychiatrists of today. Nevertheless, I argue that despite potential practical difficulties in promoting such complex views among the general public, they are indispensable in building the scientific image and on a philosophical level they constitute the crucial part of the synoptic view of depression we seek.

Apart from the focus on phenomenology and a quasi-phenomenological methodology there are two main lines of thought characteristic of the 4E approaches in general -2 of the "E's" seem especially important. The first one is the concept of embodiment, the concentration on the bodily experiences of people suffering from depression. The other is enactivism which tries to consider depression in a wide, multi-layered context of the patient's life, culture, personal history, society and environment. Phenomenological and embodied theories of depression (proposed by such authors as Ratcliffe [2008, 2012, 2015] or Ghaemi [2009, 2011]) are not at odds with more enactive ones (such as Fuchs's [2005a, 2005b, 2017]), nevertheless, there are some differences, particularly as far as a certain kind of holism apparent in enactive approaches is concerned.

\footnotetext{
${ }^{11} \mathrm{I}$ have discussed the question of how 4E theories perform from a scientific standpoint in comparison with mainstream neurobiologically oriented psychitary in another paper (Białek, forthcoming), and as it is both a complex question and an issue of no immediate interest to the subject of this essay I shall leave this matter open.
} 
Matthew Ratcliffe, who is perhaps the most well-known of the authors working on depression within the phenomenological and embodied paradigm begins his 2015 book by emphasising how people suffering from depression complain about not being able to find the right language to describe their experience (Ratcliffe, 2015, p. 2). His own purpose is, therefore, to explore philosophically "what it is like to be depressed" (p. 1). Ratcliffe does so by reflecting on the so-called "existential feeling" and how it becomes altered in depressed patients. Although his terminology is deeply grounded in phenomenology, existentialism and even Heideggerian concepts such as that of the mood and possibilities, the description he arrives at is very specific and relatable. Ratcliffe devotes much attention to the classical notions associated with depression in any existing model, such as guilt, anxiety, loss of hope and estrangement, however he examines them in light of his phenomenological approach in which depression is understood to be a thorough transformation of the patient's whole world, her attitude, the way she acts, experiences and thinks. He employs the Husserlian framework of natural attitude along with the Heideggerian concept of being in the world and the sense of belonging to show how this natural connectedness to external reality is lost in depression and how it influences any kind of mental and social acts. At the same time, he seeks to remain firmly grounded in the empirical reality of depression, working with actual patients' accounts of their own stories and their descriptions of the experience. The author also addresses the classical debate whether depression should at all be treated as a pathological state I mentioned in the context of antipsychiatry - and from his suggestions it follows that there may not be a clear cut distinction between what is still a "normal" struggle and what is "depression."

Those chapters, although the analyses performed are intellectually demanding and sophisticated, manage to elaborate on concepts that seem particularly well suited to shape the manifest image of depression and, therefore, the folk-psychiatric account. This is precisely because they involve concepts that already belong to folk theories of the human psychethe benefit Ratcliffe might bring us is his help in describing, in a nonreductive fashion, why such phenomena as guilt or hopelessness arise and also the guidance he offers in ascertaining where to look for the boundaries between "normal" and "pathological" states. Still, all this might seem a bit obvious and banal. However, Ratcliffe also develops whole new threads specific to the phenomenological and embodied approach.

The analysis of the subjective experience of depression within the $4 \mathrm{E}$ paradigm involves, not surprisingly, exploring all the aspects of bodily awareness and motor action, which are still being overlooked in the mainstream neurobiological image. Ratcliffe presents empirical evidence that depression is experienced as a disease of the body as well as of the brain, and in some cases, particularly in non-Western cultures, even predominantly so (Ratcliffe, 2015, pp. 75-78). Naturally, Ratcliffe makes use of the famous Husserlian distinction between the body as Körper, the unfeeling object we experience from a third-person perspective, and the body as Leib, the feeling body, to which we have special, first-person access via proprioception and interoception. He also adopts the notions of noematic-roughly speaking, object-like - experiences of our body, and the noetic, subjective ones and explains how in pathological states both the former and the latter become disordered and 
mixed. From a phenomenological point of view adopted by the 4E paradigm, our body and the way we experience it is crucial not only to our own awareness of ourselves but also to the aforementioned existential feeling, our embeddedness in the world, our capability of experiencing the external reality, and, last, but not least, also for our relations with other subjects. In depression, even the very way we experience space and time becomes warped, which is an old intuition among psychiatrists (cf. Minkowsky, 1970; Ghaemi, 2007) that thanks to $4 \mathrm{E}$ accounts has now been gaining increasing interest (cf. Vogel, Krämer, Schoofs, Kupke, \& Vogeley, 2018). The alteration of bodily awareness causes, therefore, a distorted, strange awareness of the world. A pathological feeling of detachment emerges. ${ }^{12}$

Because the body mediates our experience of the world, it also provides us with a point of view, an anchor for our egocentric perspective. Without one, the salience of different elements in our surroundings becomes disproportionate, we lose the easy intuitive way we normally appraise them as being relevant or irrelevant to our needs and wants. In consequence, we may feel lost and unguided. Without a shared embeddedness in the environment it also becomes increasingly difficult to engage with other people.

It is important to note that this strong emphasis on the reciprocal relation between the subject and her external reality in the analysis of depression is not only missing from, but even at odds with the dominant psychiatric and folk-psychiatric internalist view of the disease. The contemporary mainstream account of depression is internalist in at least two senses of the term. Firstly, ,internalism” refers here to a claim that all the causes, mechanisms and possible cures for depression are to be found literarily inside the head, namely: in the brain. More precisely: somewhere within the complex network of neurons that are malfunctioning due to an imbalance of neurotransmitters. Even taking into account that the most widely accepted model in current psychiatry is Engel's biopsychosocial model, ${ }^{13}$ it has never been made entirely clear how the psychological and social factors it includes are to be actually incorporated (cf. Ghaemi's [2009, 2011] criticism). Although an increasing number of psychiatrists engage in psychosocially oriented projects, it is still the search for neurobiological causes that remains the holy grail of the most of the reductionist mainstream.

The other classic philosophical meaning of ,internalism” is more metaphorical; it comprises the subjective experiences that originate ,within” the mind of the subject as opposed to the external reality. On the face of it, some of the contemporary phenomenologically inspired explanations of depression seem to be leaning that way, but for the philosophical and theoretical reasons revealed above no true $4 \mathrm{E}$ account could ever focus solely on subjective

\footnotetext{
${ }^{12}$ Although this is not of immediate importance to the subject of this paper, I need to note that other authors such as Zahavi, Sass and Parnas provide a very similar account of different psychopathologies such as schizophrenia (cf. Zahavi, Sass \& Parnas, 2011) and often the distinctions between various disorders appear to be blurred. It may just be another proof that the whole system of clear cut distinctions and psychiatric categories needs to be reworked - but it also may be considered a weakness of the 4E approach.

${ }^{13}$ Engel's seminal 1977 paper introduced the idea of including the psychological and social dimensions of diseases in medical practice and treating the patient holistically, and not as a set of separate organs, it is not clear to what degree it was in fact adopted. For more details about the model see also Borrell-Carrió et al., 2004.
} 
experiences, important as they are. Even so, among this family of theories there is one that puts even more emphasis on leaving the internalist picture as far behind as it is only possible.

Thomas Fuchs presents an account of depression as a circular process in which what happens at the level of the brain is just one level (the micro-level) of a three-tier structure incorporating the so called meso-level of interactions between the brain, organism and the environment and the macro-level of social interactions (Fuchs, 2017, p. 256), and all the tiers are connected by both top-down and bottom-up relations, thus creating both vertical and horizontal causation and various feedback loops at different levels. A specific type of holism is characteristic of any enactive theory: all phenomena can only be considered in light of the whole structure of our being in the world, from the micro-processes taking place in our neural structures, through our bodily behaviours and experiences, right to complex actions and the richness of our social and cultural context. Ezequiel Di Paolo, Elena Cuffari and Hanne De Jaegher (2018) have even just put forth an ambitious theory of the development of our linguistic (and mental) capabilities which is built in a bold, holistic, Hegelian fashion, by employing their concept of participatory sense-making to a huge range of increasingly complex phenomena, from simple biological behaviours up to our cultural life.

This kind of approach to depression goes far beyond the vague biopsychosocial model; an enactivist would claim that we simply cannot define or understand any mental disorder without taking into account the whole complex structure of human life. "Depression results from a perceived loss of meaning and social resonance, not from a lack of serotonin" (Fuchs, 2017, p. 263). In consequence, also in the choice of treatment we no longer should be focusing only on drugs that target neural mechanisms in the brain - a therapeutic intervention changing the patient's environment, her living conditions or her bodily functions could be at least equally effective if not more so. Although Fuchs acknowledges the progress being made in studying the influence of the so-called external factors on the development of mental disorders, ${ }^{14}$ he underlines that the search for a direct neurobiological impact of certain events is futile.

There is no direct impact of environmental factors on the brain - brain concussion left aside. What changes brain structures enduringly are the experiences a person makes in her social environment. However, these experiences may not be described from a third-person perspective, for they are bound to consciousness, communication, and relationships (Fuchs, 2017, p. 265)

Albeit Fuchs is quite decisive in his criticism of neurobiological reductionism, he is, of course, not opposed in any way to including neurobiology in psychiatric explanations. His claim is rather that without a good grasp of how complex and deeply intertwined with one another are the processes taking place when a person becomes depressed, those explanations are misguided. It is not some fictitious "neural correlate of sadness" or even of a certain traumatic experience that "cause" depression — if anything, it's the complex web

\footnotetext{
${ }^{14}$ In the enactivist picture, it does not really make much sense to differantiate between ,external” and ,internal” factors, all factors are elements of a complex system.
} 
of neural, behavioural, psychological and social mechanisms behind the multifaceted feedback loops connecting our bodily self-awareness and social interactions. A description of the neurobiological level alone will never be sufficient.

An important aspect of enactive theories is that because of their holistic approach, they allow us to re-examine what we consider the actual essence of depression-and the answer may be different according to different people suffering from it. In the current folk-psychiatric account, one of the key issues seems to be the inability to perform one's duties. We are used to alarming scientific and mass media reports of a "rising depression epidemics" that results in terrifying "economic costs" because of all the lost productivity and missed work-days (cf. for example Trautmann, Rehm, \& Wittchen, 2016). As I mentioned, in many of the $19^{\text {th }}$ century accounts cited by Marcinów, depression was seen in a moral and legal context, as a potential mitigating circumstance in case of a crime or a cause of cognitive deficiencies. Now-it is our usefulness in the capitalist society that seems to influence the most how this illness is perceived, and some authors (including the ones I mentioned in the context of the modern wave of scepticism about the biomedical model of psychiatry, but cf. especially the widely commented book by Hari [2018]) express serious worries about this influence. It is dangerous mostly because it's implicit in the scientific image of depression - and it has not been made explicit in any way in the reception of this image in folk psychiatry. The enactive model that places such importance on the sociological and cultural implications of depression forces us to be aware of the limitations of neurobiological and internalist approaches within the scientific image. It would enable the folk-psychiatrist to gain much needed awareness and perspective regarding the various social dimensions of psychiatric disorders.

\section{Concluding Remarks: On Our Way to Creating the Synoptic View}

It is time to examine whether 4E theories could actually remedy some of the problems I sketched in the first part of this paper. Let me first focus on the manifest image alone and the issue of folk psychiatry.

I have identified various reasons why the current, mainstream, naively reductionist manifest image of depression cannot even serve the normal purpose of a folk theory, let alone constitute a good partial ground for a synthetic synoptic view of depression. I concluded, that a richer, more meaningful language to speak about depression is needed. In particular, it must enable people to describe their first-personal experience and depression as a mental disorder must always be examined in a wider context. It is imperative to take into account various social and cultural factors, and to do it in such a way that the illness would cease to be seen as some kind of individual fault or an isolated mechanical failure of a mysterious neural circuit.

From the way I presented the key features of two most important 4E approaches to depression it is clear, that they seem very well fitted to fulfil all three of those tasks. Despite often complex phenomenological terminology, the essence of the phenomenological analyses would go a long way in bridging the explanatory gap left by the traditional manifest 
image. The very essence of phenomenological psychiatry is to concentrate on the actual, first-person experience of patients, on the way their bodily awareness influences their relations with others and their ability to act in their environment. Ratcliffe's analyses involve meaningful notions like hope or regret which used to be present in the manifest image of depression - however, his careful philosophical analysis of such notions has the capability to shape the vague, folk understanding of such concepts. Although Ratcliffe's intricate philosophical analysis of the loss of hope, of the fixation on the past and on the existential regret present in depression will never be fully accessible for the general public, the very concepts are much less abstract than "neurotransmitters." They also still belong in folkpsychiatric explanations of the behaviours and experiences of depressed people. However, so far the neurobiological, reductionist scientific image of depression has been encouraging the folk-psychiatrist to discard such notions, to try to replace them with what is truly perceived to be well-founded and scientific, with statements about serotonin and brain disease. Similarly, the focus on the workings of the whole body and its experiences might be very useful in everyday life. $4 \mathrm{E}$ theories may offer many useful tools for the folk psychiatrists, emphasising that it is not only the isolated brain that suffers in depression, that being depressed does not only concern the level of emotions and beliefs - it influences the whole motoric behaviour and the basic ways of experiencing the world.

$4 \mathrm{E}$ theories may also prove to be a safe way to modify and enrich the manifest image without turning folk-psychiatrists into depression denialists. Although they might initially raise more scepticism towards the still dominant biomedical scientific image of the disease and, in particular, towards pharmacological treatment, 4E theories are not antipsychiatric. Moreover, the commonsensical enactivist understanding of holistic approach in psychiatry and the fact it does not drive us away from sound, evidence-based medicine the way various "holistic" ideas do-is simply much needed both in the scientific world and in the general public.

It is important to understand that the role of $4 \mathrm{E}$ theories in constructing the scientific image is manifold. They do not simply offer a rival scientific image. By adopting vastly different methodological approaches to reductionist psychiatry and bringing in phenomenological attention to the qualitative analysis of experience and enactivist holism they change the very structure of the image. It is no longer disconnected from the manifest image - it attempts to truly satisfy the explanatory needs behind it. Therefore, the relation between manifest and scientific images is in this case a two-way one. For example, the tools offered by this approach, so far directed specifically at diagnosing and treating schizophreniathe EASE, EAWE and EAFI questionnaires - enable clinicians to conduct in-depth qualitative, semi-structured interviews with patients and truly grasp their experience of their own mental issues. ${ }^{15}$ Also, none of the $4 \mathrm{E}$ theories lie in the way of the search for neurobiological correlates and causes of depression, they do, however, invite various big and small changes in the way we perform the search, and they suggest specific areas for further study. To adopt a 4E approach also forces us to become more conscious, at the meta-level,

\footnotetext{
${ }^{15}$ For details about the EASE, EAWE and EAFI questionnaires (cf. Parnas et al., 2005 [EASE]; Sass et al. 2017 [EAWE] and Rasmussen, Stephensen, \& Parnas., 2018 [EAFI]).
} 
of the methodological choices we make in studying, diagnosing and treating depression, as this family of conceptions always emphasises the multi-layered and multifaceted structure of the disease, its aetiology and possible therapeutic interventions. If the current crisis concerning the status of neurobiological reductionism in psychiatry is to be resolved, such help should only be welcome.

Therefore, I would like to conclude that $4 \mathrm{E}$ theories are not only a means to enrich both the manifest and the scientific image of depression. They are the best possible way to achieve an acceptable synoptic view, one that allows for the scientific image to support folk-psychiatrists, but also for the real explanatory needs of the folk psychiatrist to be taken into consideration by science.

I have argued that the current situation is deeply unsatisfying both from a scientific and from a socio-political point of view, and it might potentially lead to dangerous processes, should the reductionist model of psychiatry suffer further blows from its critics. The casestudy of Marcinów's 2018 book on the history of Polish psychiatry and its reception enabled me to bring out the key needs of a folk-psychiatrist which are not being met by the current manifest image. The currently dominant scientific image of depression cannot rectify this situation - on the contrary, it actually compounds the problem. Given that the status of the reductionist image itself is becoming increasingly unstable, there is a very real need for a new approach. As I have shown in some detail, 4E theories may, however, inspire some modest optimism. The general public is obviously ready for a fresh approach to mental disorders, and, in particular, to depression. And philosophers of psychiatry may be able to provide it.

\section{References}

Borrell-Carrió, F., Suchman, A., Epstein, R. (2004). The Biopsychosocial Model 25 Years Later: Priciples, Practice, and Scientific Inquiry. Annals of Family Medicine, 2(6), 576-582. https://doi.org/10.1370/afm.245

Brossard, D., \& Scheufele, D. A. (2013). Science, new media, and the public. Science, 339(6115), 40-41. https://doi.org/10.1126/science.1232329

Bracken P, Thomas P. (2001). Postpsychiatry: A new direction for mental health. British Medical Journal, 322, 724-727. https://doi.org/10.1136/bmj.322.7288.724

Buck, A. (2008). Depression: What you need to know. Practice Nurse, 36(10), 16-19.

Cipriani, A., Furukawa, T., Salanti, G., Chaimani, A., Atkinson, L., Ogawa, ... Geddes, J. (2013). Comparative efficacy and acceptability of 21 antidepressant drugs for the acute treatment of adults with major depressive disorder: a systematic review and network meta-analysis. The Lancet, 391(10128), 1357-1366. https://doi.org/10.1016/S0140-6736(17)32802-7

Di Paolo, E., Cuffari, E., \& De Jaegher, H. (2018). Linguistic Bodies. The Continuity between Life and Language. Cabridge, MA: MIT Press. https://doi.org/10.7551/mitpress/11244.001.0001 
Engel, G. (1977). The Need for a New Medical Model: A Challenge for Biomedicine. Science, 196(4286), 129-136. https://doi.org/10.1126/science.847460

Fodor, J. A. (1985). Mind Association Fodor's Guide to Mental Representation: The Intelligent Auntie's Vade-Mecum. Mind, 94(373), 76-100. https://doi.org/10.1093/mind/XCIV.373.76

Fuchs T. (2005a). Corporealized and disembodied minds: a phenomenological view of the body in melancholia and schizophrenia. Philosophy, Psychiatry, and Psychology, 12(2), 95-107.

Fuchs T. (2005b). The phenomenology of the body, space and time in depression. Comprendre, 15, $108-121$.

Fuchs, T., (2017). Ecology of the Brain: The Phenomenology and Biology of an Embodied Mind. Oxford, UK: Oxford University Press. https://doi.org/10.1093/med/9780199646883.001.0001

Geddes, J. (2013). Comparative efficacy and acceptability of 21 antidepressant drugs for the acute treatment of adults with major depressive disorder: a systematic review and network metaanalysis. The Lancet, 391(10128), 1357-1366. https://doi.org/10.1016/S0140-6736(17)328027

Ghaemi, S. N. (2007). Feeling and Time: the Phenomenology of Mood Disorders, Depressive Realism and Existential Psychotherapy. Schizophrenia Bulletin, 33(1), 122-130.

Ghaemi, S. N. (2009). The rise and fall of the bio-psychosocial model. British Journal of Psychiatry 195(1), 3-4.

Ghaemi, S. N. (2011). The Biopsychosocial Model in Psychiatry: A Critique. Existenz, 6, 1-8.

Greenberg G. (2011). Manufacturing Depression: The Secret History of a Modern Disease. New York, NY: Simon \& Schuster.

Haslam, N., Ban, L., \& Kaufmann, L. (2007). Lay conceptions of mental disorder: The folk psychiatry model. Australian Psychologist, 42(2), 129-137. https://doi.org/10.1080/00050060701280615

Hari, J. (2018). Lost Connections: Uncovering the Real Causes of Depression-and Unexpected Solutions. Bloomsbury.

Hund, O. (2018). Psy ras drobnych. Kraków, Poland: Korporacja Ha!art.

Insel, T., Cuthbert, B., Garvey, M., Heinssen, R., Pine, D. S., Quinn, K., Sanislow, C., Wang, P. (2010). Research domain criteria (RDoC): Toward a new classification framework of research on mental disorders. American Journal of Psychiatry, 167(7), 748-751. https://doi.org/10.1176/appi.ajp.2010.09091379

Jackson, F., \& Pettit, P. (1990). In defence of folk psychology. Philosophical Studies, 59(1), 31-54. https://doi.org/10.1007/BF00368390

Kirsch, I. (2009). The Emperor's New Drugs: Exploding the Antidepressants Myth. London, UK: Random House Group.

Kirsch, I. (2014). Antidepressants and the placebo effect. Zeitschrift Fur Psychologie / Journal of Psychology, 222(3), 128-134. https://doi.org/10.1027/2151-2604/a000176

Lewis, D. (1972). Psychophysical and theoretical identifications. Australasian Journal of Philosophy, 50(3), 249-258. https://doi.org/10.1080/00048407212341301 
Longdon, E., \& Read, J. (2017). 'People with problems, not patients with Illnesses': Using psychosocial frameworks to reduce the stigma of psychosis. Israel Journal of Psychiatry and Related Sciences, 54(1), 24-30.

Minkowski, E. (1970). Lived Time: Phenomenological and Psychopathological Studies. Evanston, IL: Northwestern University Press.

Moncrieff, J. (2013). The Bitterest Pills: The Troubling Story of Antipsychotic Drugs. Basingstoke, UK: Palgrave Macmillan. https://doi.org/10.1057/9781137277442

Parnas, J., Moller, P., Kircher, T., Thalbitzer, J., Jansson, L., Handest, P., \& Zahavi, D. (2005). EASE: Examination of Anomalous Self-Experience. Psychopathology, 38(5), 236-258. https://doi.org/10.1159/000088441

Rasmussen, A. R., Stephensen, H., \& Parnas, J. (2018). EAFI: Examinatgion of Anomalous Fantasy and Imagination. Psychopathology, 51(3), 216-226. https://doi.org/10.1159/000488464

Ratcliffe, M. (2008). Feelings of Being. Oxford, UK: Oxford University Press. https://doi.org/10.1093/med/9780199206469.001.0001

Ratcliffe, M. (2012). Varieties of Temporal Experience in Depression. The Journal of Medicine and Philosophy, 37(2), 114-138. https://doi.org/10.1093/jmp/jhs010

Ratcliffe, M. (2015). Experiences of Depression: A Study in Phenomenology. Oxford, UK: Oxford University Press.

Rutjens, B. T., Heine, S. J., Sutton, R. M., \& van Harreveld, F. (2018). Attitudes towards science. Advances in Experimental Social Psychology, 57, 125-165. https://doi.org/10.1016/bs.aesp.2017.08.001

Sass, L., Pienkos, E., Skodlar, B., Stanghellini, G., Fuchs, T., Parnas, J., \& Jones, N. (2017). EAWE: Examination of Anomalous World Experience. Psychopathology, 50(1), 10-54. https://doi.org/10.1159/000454928

Schomerus, G., Schwahn, C., Holzinger, A., Corrigan, P. W., Grabe, H. J., Carta, M. G., \& Angermeyer, M. C. (2012). Evolution of public attitudes about mental illness: A systematic review and meta-analysis. Acta Psychiatrica Scandinavica, 125(6), 440-452. https://doi.org/10.1111/j.1600-0447.2012.01826.x

Shorter, E. (2015). The history of nosology and the rise of the Diagnostic and Statistical Manual of Mental Disorders. Dialogues in Clinical Neuroscience, 17(1), 59-67.

Stephan, K. E., Bach, D. R., Fletcher, P. C., Flint, J., Frank, M. J., Friston, K. J. ... Breakspear, M. (2016a). Charting the landscape of priority problems in psychiatry, part 1: Classification and diagnosis. Lancet Psychiatry, 3(1), 77-83. https://doi.org/10.1016/S2215-0366(15)00361-2

Stephan, K. E., Bach, D. R., Fletcher, P. C., Flint, J., Frank, M. J., Friston, K. J. ... Breakspear, M. (2016b). Charting the landscape of priority problems in psychiatry, part 2: pathogenesis and aetiology. Lancet Psychiatry, 3(1), 84-90. https://doi.org/10.1016/S2215-0366(15)00360-0

Trautmann, S., Rehm, J., \& Wittchen, H. (2016). The economic costs of mental disorders. EMBO Reports, 17(9), 1245-1249. https://doi.org/10.15252/embr.201642951 
Uher, R., Payne, J. L., Pavlova, B., \& Perlis R. H. (2014). Major depressive disorder in DSM-5: implications for clinical practice and research of changes from DSM-IV. Depression and Anxiety 31(6), 459-471. https://doi.org/10.1002/da.22217

Vogel, D. H. V., Krämer, K., Schoofs, T., Kupke, C., \& Vogeley, K. (2018). Disturbed Experience of Time in Depression-Evidence from Content Analysis. Frontiers in Human Neuroscience, 12(February), 1-10. https://doi.org/10.3389/fnhum.2018.00066

Wakefield, J., First, M. (2012). Fallacious reasoning in the argument to eliminate the major depression bereavement exclusion in DSM-5. World Psychiatry, 11(3), 204-205. https://doi.org/10.1002/j.2051-5545.2012.tb00135.x

Sass, L., Parnas, J., Zahavi, D. (2011). Phenomenological Psychopathology and Schizophrenia: Contemporary Approaches and Misunderstandings. Philosophy, Psychiatry and Psychology, 18(1), 1-23. https://doi.org/10.1353/ppp.2011.0008

Szasz, T. (1961). The Myth of Mental Illness. New York, NY: Hoeber-Harper.

Żurek, Ł. (2018). W szpitalu wali handlem. [A review of Hund 2018]. Dwutygodnik, 245. Retrieved from https://www.dwutygodnik.com/artykul/7982-w-szpitalu-wali-handlem.html

The editorial and publishing process of this publication has been financed by the Ministry of Science and Higher Education from the funds for the dissemination of research (DUN) within the framework of publishing activity, contract no. 711/P-DUN/2019, period of implementation: the years 2019-2020. 